\section{TINJAUAN AKUSTIK PERANCANGAN INTERIOR GEDUNG PERTUNJUKAN}

\section{Dwi Retno Sri Ambarwati}

\section{Fakultas Bahasa dan Seni Universitas Negeri Yogyakarta}

\section{Abstract}

Many factors must be considered in the planning of the acoustic of interior auditorium according to its function, so that the performance of the artists or actors can be caught better and the quality of the show is able to satisfy the audience. Especial conditions that must be fulfilled in the planning of the acoustic of interior auditorium are: enough loudness by shortening the distance of the audience with the sound, heightening the source of sound, the accompaniment of the floor, encircle the source of sound by the voice reflector, the dimension of room must match with the space volume, avoiding parallel sound reflector and locate the audiences in the beneficial area. Other conditions are the right for of the handicaps of acoustic and the form treatment of floo, wall and plafond and also veneering them with the sound absorber material. Financial consideration usually represent the constrictor of the acoustic repair, because getting a good quality of acoustic cost a lot of money.

Keyword: acoustics, auditorium, and interior building

\section{PENDAHULUAN}

Gedung Pertunjukan merupakan suatu tempat yang dipergunakan untuk mempergelarkan pertunjukan, baik seni tari, musik maupun drama. Terkait dengan itu maka persyaratan ruang harus dipenuhi sesuai dengan fungsinya, agar pesan yang diungkapkan penyaji seni dapat tertangkap dengan baik sehingga tercapai kualitas pertunjukan yang optimal serta kepuasan bagi penikmatnya mengingat penonton yang memasuki sebuah gedung pertunjukan memiliki hak untuk mendapatkan kenyamanan, keamanan, penerangan yang cukup, pemandangan (viewing) yang menyenangkan dan kualitas bunyi yang baik selain kualitas acaranya itu sendiri

Sesuai dengan fungsi utamanya yaitu sebagai gedung pertunjukan, salah satu persyaratan yang seharusnya dipenuhi selain tata cahaya adalah penataan akustik atau tata suara. Pengolahan tata suara yang baik akan mempertinggi kualitas tampilan pertunjukan dan menciptakan kenyamanan bagi penikmatnya.

Akustik diartikan sebagai sesuatu yang terkait dengan bunyi atau suara, sebagaimana pendapat Shadily (1987:8) bahwa akustik berasal dari kata dalam bahasa Inggris :acoustics, yang berarti ilmu suara atau ilmu bunyi. Halme (1990:12) menyebutkan: Acoustics is a science and the first consideration to get a comfortable sound environment, bahwa akustik merupakan suatu ilmu dan merupakan pertimbangan pertama untuk mendapatkan lingkungan suara yang nyaman, sebagaimana pendapatnya:

Jadi Tata Akustik merupakan pengolahan tata suara pada suatu ruang untuk menghasilkan kualitas suara yang nyaman untuk dinikmati, merupakan unsur penunjang terhadap keberhasilan desain yang baik karena pengaruhnya sangat luas dan dapat menimbulkan efek-efek fisik dan emosional dalam ruang sehingga seseorang akan mampu merasakan kesan-kesan tertentu.

\section{PERILAKU BUNYI (BEHAVIOUR OF SOUND)}

\section{Perilaku Bunyi (Behaviour of Sound) di Ruang Tertutup}

Berdasarkan sumber yang didapat dari http://Acoustics.com bunyi di dalam ruang tertutup (enclosed space) memiliki perilaku (behaviour) tertentu jika menumbuk dinding-dinding dari ruang tertutup tersebut yakni energinya akan dipantulkan (reflected), diserap (absorbed), disebarkan (diffused), atau dibelokkan (diffracted) tergantung pada sifat akustik dindingnya.

Bunyi akan memantul apabila menabrak beberapa permukaan sebelum sampai ke pendengar sebagaimana pendapat Mills(1986: 27): Reflected sound strikes a surface or several surfaces before reaching the receiver. Pemantulan dapat diakibatkan oleh bentuk ruang maupun bahan pelapis permukaannya. Permukaan pemantul yang cembung akan menyebarkan gelombang bunyi sebaliknya permukaan yang cekung seperti bentuk dome (kubah) dan permukaan yang lengkung menyebabkan pemantulan bunyi yang mengumpul dan tidak menyebar sehingga terjadi pemusatan bunyi.

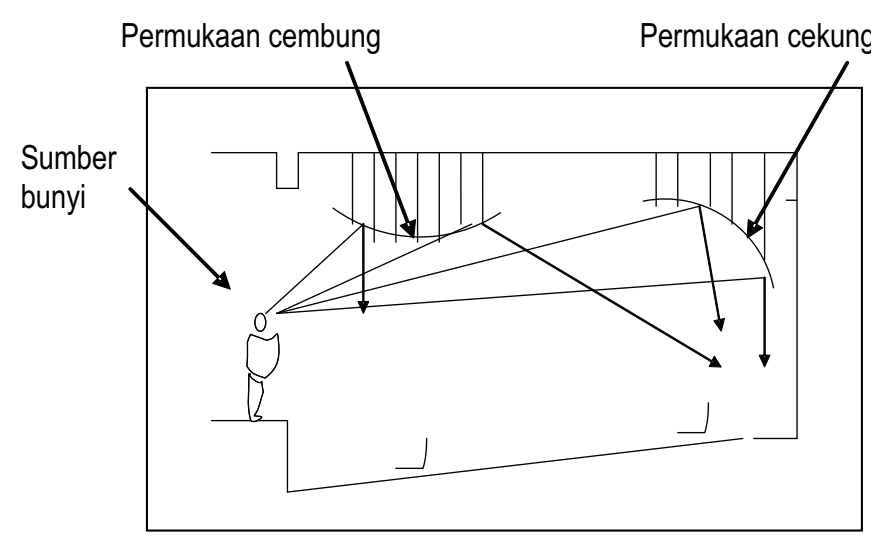

Gambar 1. Pemantulan suara ke langit-langit Sumber: Doelle (1990) 
Permukaan penyerap bunyi dapat membantu menghilangkan permasalahan gema maupun pemantulan yang berlebihan.

Saat bunyi menabrak permukaan yang lembut dan berpori maka bunyi akan terserap olehnya (Doelle, 1990:26) sehingga permukaan tersebut disebut penyerap bunyi. Bahan-bahan tersebut menyerap bunyi sampai batas tertentu, tapi pengendalian akustik yang baik membutuhkan penyerapan bunyi yang tinggi. Adapun yang menunjang penyerapan bunyi adalah lapisan permukaan dinding, lantai, langit-langit, isi ruang seperti penonton dan bahan tirai, tempat duduk dengan lapisan lunak, karpet serta udara dalam ruang.

Bunyi dapat menyebar menyebar ke atas, ke bawah maupun ke sekeliling ruangan. Suara juga dapat berjalan menembus saluran, pipa atau koridor.ke semua arah di dalam ruang tertutup. Seperti yang tersebut dalam Acoustic.com: Sound can flank over, under, or around a wall. Sound can also travel through common ductwork, plumbing or corridors.

Difraksi bunyi merupakan gejala akustik yang menyebabkan gelombang bunyi dibelokkan atau dihamburkan di sekitar penghalang seperti sudut (corner), kolom, tembok dan balok.

\section{Persyaratan Akustik Perancangan Ruang Gedung Pertunjukan}

Persyaratan tata akustik gedung pertunjukan yang baik dikemukakan oleh Doelle (1990:54) yang menyebutkan bahwa untuk menghasilkan kualitas suara yang baik, secara garis besar gedung pertunjukan harus memenuhi syarat kekerasan (loudness) yang cukup, bentuk ruang yang tepat, distribusi energi bunyi yang merata dalam ruang, dan ruang harus bebas dari cacat-cacat akustik.

\section{Kekerasan (Loudness) yang Cukup}

Kekerasan yang kurang terutama pada gedung pertunjukan ukuran besar disebabkan oleh energi yang hilang pada perambatan gelombang bunyi karen jarak tempuh bunyi terlalu panjang, dan penyerapan suara oleh penonton dan isi ruang (kursi yang empuk, karpet, tirai).

Hilangnya energi bunyi dapat dikurangi agar tercapai kekerasan/loudness yang cukup. Dalam hal ini Doelle (1990:54) mengemukakan persyaratan yang perlu diperhatikan untuk mencapainya, yaitu dengan cara memperpendek jarak penonton dengan sumber bunyi, penaikan sumber bunyi, pemiringan lantai, sumber bunyi harus dikelilingi lapisan pemantul suara, luas lantai harus sesuai dengan volume gedung pertunjukan, menghindari pemantul bunyi paralel yang saling berhadapan, dan penempatan penonton di area yang menguntungkan.

Mills (1976: 15) mengemukakan pendapat mengenai persyaratan jarak penonton dengan sumber bunyi untuk mendapatkan kepuasan dalam mendengar dan melihat pertunjukan:No seat should be more than $20 \mathrm{~m}$ from the stage front if the performance is to be seen and heard clearly.Jarak tempat duduk penonton tidak boleh lebih dari 20 meter dari panggung agar penyaji pertunjukan dapat terlihat dan terdengar dengan jelas.

Akan tetapi untuk mendapatkan kekerasan yang cukup saja (tanpa harus melihat penyaji dengan jelas), misalnya pada pementasan orkestra atau konser musik, toleransi jarak penonton dengan penyaji dapat lebih jauh hingga jarak maksimum dengan pendengar yang terjauh adalah $40 \mathrm{~m}$, sebagaimana yang dikemukakan Mills (1976:8). The maximum distance between the orchestra and the further listeners, about $40 \mathrm{~m}$.

Sumber bunyi harus dinaikkan agar sebanyak mungkin dapat dilihat oleh penonton, sehingga menjamin gelombang bunyi langsung yang bebas (gelombang yang merambat secara langsung tanpa pemantulan) ke setiap pendengar.

Lantai di area penonton harus dibuat miring karena bunyi lebih mudah diserap bila merambat melewati penonton dengan sinar datang miring (grazing incidence). Aturan gradien kemiringan lantai yang ditetapkan tidak boleh lebih dari $1: 8$ atau $30^{\circ}$ dengan pertimbangan keamanan dan keselamatan. Kemiringan lebih dari itu menjadikan lantai terlalu curam dan membahayakan.

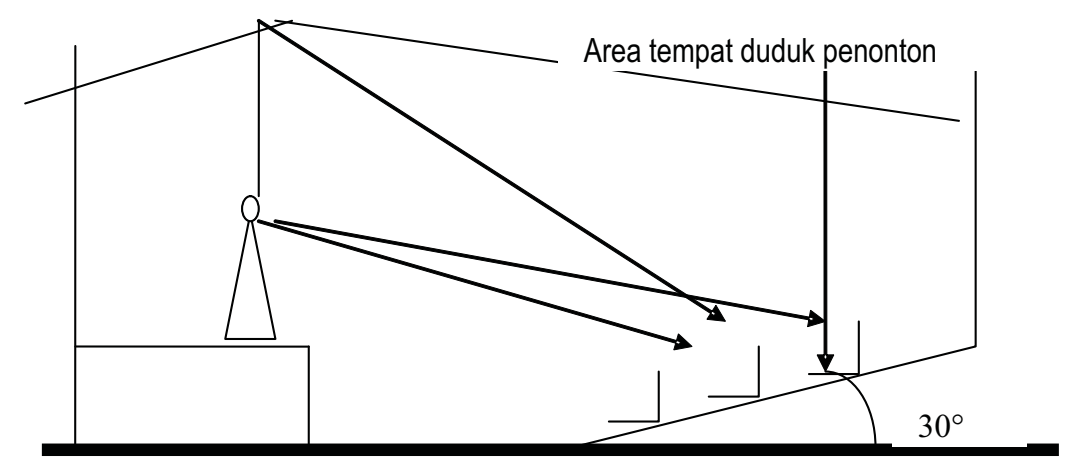

Gambar 2. Penaikan sumber bunyi dan pemiringan lantai area penonton Sumber: Doelle (1990)

Gambar di atas menjelaskan pemiringan lantai dan peninggian sumber bunyi. Bila sumber bunyi ditinggikan dan area tempat penonton dimiringkan $30^{\circ}$ maka pendengar akan menerima lebih banyak bunyi langsung yang menguntungkan kekerasan suara.

Untuk mencegah berkurangnya energi suara, sumber bunyi harus dikelilingi oleh permukaan-permukaan pemantul bunyi seperti gypsum board, plywood, flexyglass dan sebagainya dalam jumlah yang cukup banyak dan besar untuk memberikan energi bunyi pantul tambahan pada tiap bagian daerah penonton, terutama pada tempat-tempat duduk yang jauh .Langit-langit dan 
dinding samping auditorium merupakan permukaan yang tepat untuk memantulkan bunyi. Sehubungan dengan upaya penguatan bunyi tersebut Mills (1976:28) berpendapat sebagai berikut.

One way of reinforcing sound from the stage is to provide reflectors above the front part of the auditorium to direct the sound to the back seats, where the direct sound is weakest; in some cases, the auditorium ceiling itself might be an appropriate reflecting surface.

Jadi salah satu cara untuk memperkuat bunyi dari panggung adalah dengan menyediakan pemantul di atas bagian depan auditorium untuk memantulkan bunyi secara langsung ke tempat duduk bagian belakang, dimana bunyi langsung (direct sound) terdengar paling lemah.

Permukaan-permukaan pemantul bunyi (acoustical board, plywood, gypsum board dan lain-lain) yang memadai akan memberikan energi pantul tambahan pada tiap-tiap bagian daerah penonton, terutama pada bagian yang jauh.Ukuran permukaan pemantul harus cukup besar dibandingkan dengan dengan panjang gelombang bunyi yang akan dipantulkan. Sudut-sudut permukaan pemantul harus ditetapkan dengan hukum pemantulan bunyi dan langit-langi serta permukaan dinding perlu dimanfaatkan dengan baik agar diperoleh pemantulan-pemantulan bunyi singkat yang tertunda dalam jumlah yang terbanyak.

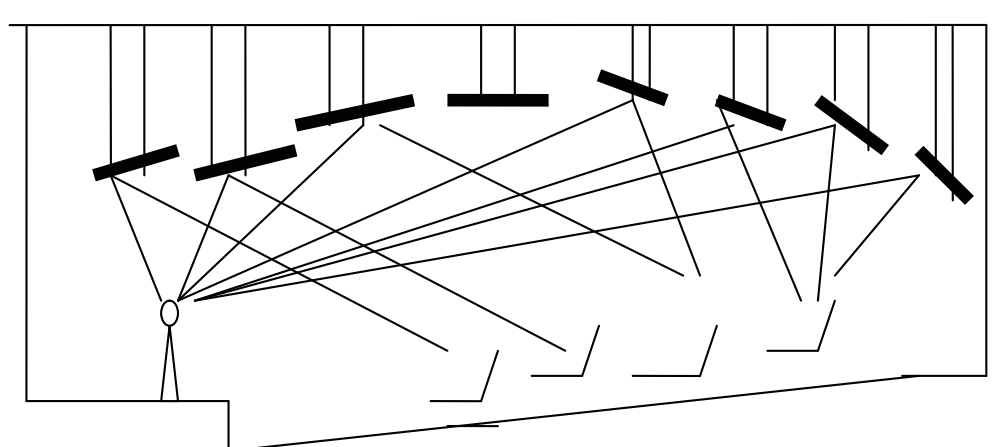

Gambar 3. Penempatan langit-langit pemantul Sumber: Doelle (1990)

Gambar di atas menjelaskan bahwa ketepatan dalam meletakkan langitlangit pemantul dengan pemantulan bunyi yang makin banyak ke tempat duduk yang jauh, secara efektif menyumbang kekerasan yang cukup. Langit-langit dan bagian depan dinding-dinding samping auditorium merupakan permukaan yang cocok untuk digunakan sebagai pemantul bunyi.
Terkait dengan kapasitas tempat duduk, The Association of British Theatre Technicians dalam Mills( 1976) mengklasifikasikan gedung pertunjukan dari yang berukuran kecil hingga sangat besar yakni: ukuran sangat besar berkapasitas 1500 atau lebih tempat duduk, ukuran besar 900-1500 tempat duduk, ukuran sedang 500 -900 tempat duduk dan ukuran kecil kurang dari 500 tempat duduk.

Doelle (1990) menyebutkan bahwa nilai volume per tempat duduk penonton yang direkomendasikan untuk gedung pertunjukan serbaguna minimal $5.1 \mathrm{~m}^{3}$ (m cubic), optimal $7.1 \mathrm{~m}^{3}$ dan maksimal $8.5 \mathrm{~m}^{3}$. Dari perbandingan tersebut dapat diperoleh standar ukuran volume yang dipersyaratkan untuk gedung ukuran tertentu sehingga kelebihan ataupun kekurangan kapasitas ruang dapat dihindari dianjurkan.

Bentuk plafond paralel secara horisontal seperti gambar di bawah ini tidak

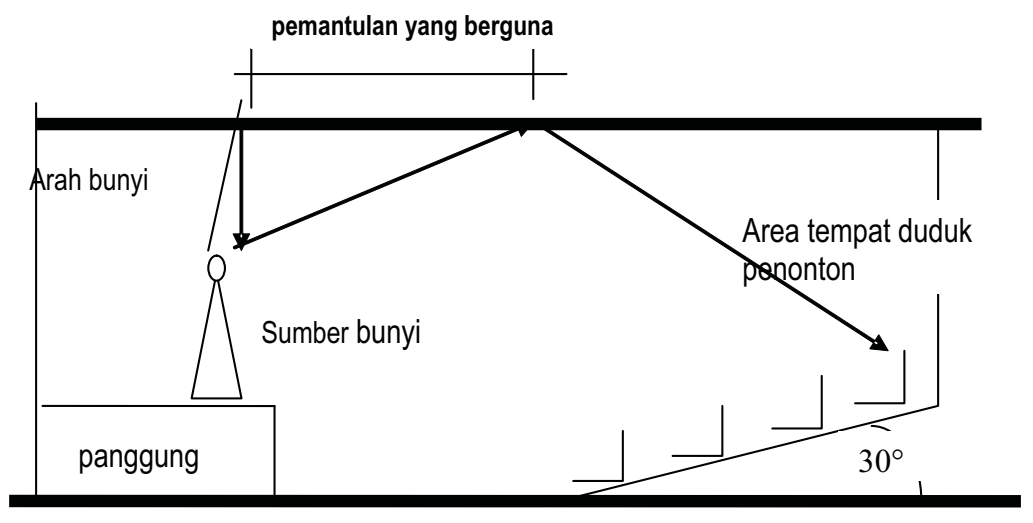

Gambar 4. Bentuk plafond paralel yang tidak dianjurkan Sumber: Doelle (1990)

Pada gambar di atas terjadi pemantulan kembali sebagian besar bunyi langsung (direct sound) ke sumber bunyi, dan sebagian lagi dipantulkan ke langitlangit dengan waktu tunda singkat yang terbatas baru kemudian disebarkan ke arah penonton sehingga bunyi langsung yang diterima penonton lebih sedikit sehingga kekerasan sangat berkurang.

Disarankan bentuk permukaan pemantul bunyi yang miring dengan permukaan yang tidak beraturan, terutama daerah plafond di atas sumber bunyi, agar sebagian besar bunyi langsung (direct sound) menyebar ke arah penonton dengan waktu tunda yang panjang sehingga bunyi langsung dapat diterima sebagian besar penonton hingga ke tempat duduk terjauh.

Bentuk plafond yang dianjurkan 


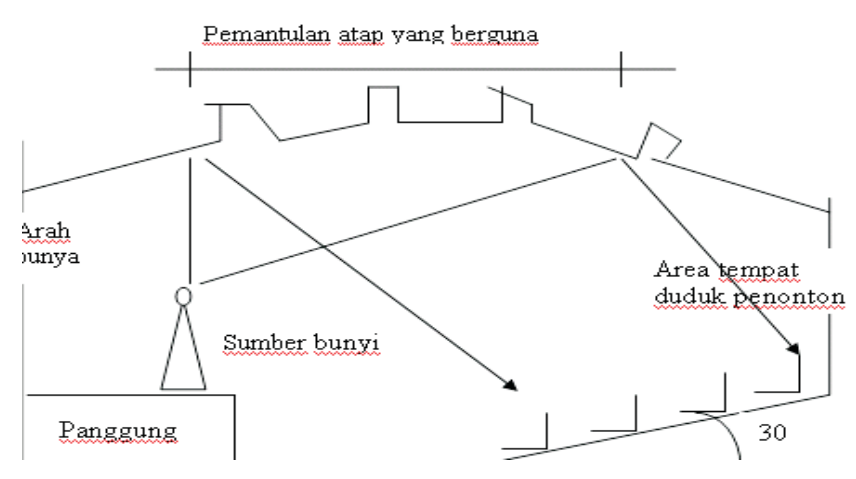

Gambar 5. Pemantulan yang dianjurkan Sumber: Doelle (1990)

Penonton harus berada di daerah yang menguntungkan, baik saat menonton maupun melihat pertunjukan, yakni berada pada area sumbu longitudinal.

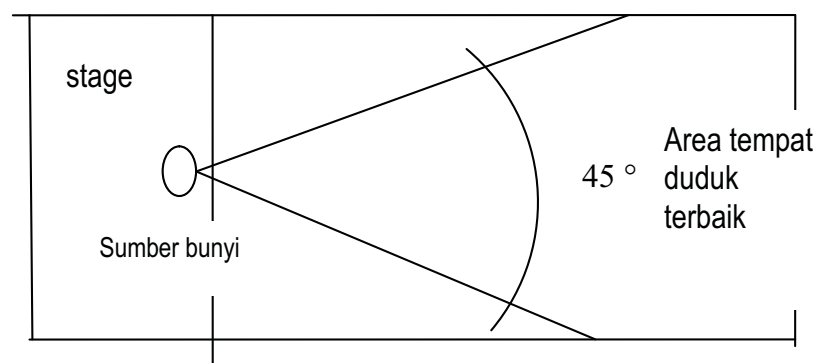

Gambar 6. Area sumbu longitudinal Sumber: Doelle (1990)

Area sumbu longitudinal merupakan area untuk pendengaran dan penglihatan terbaik, sehingga harus diefektifkan untuk tempat duduk. Harus dihindari perletakan lorong sirkulasi di area ini.

Selain ditinjau dari kualitas mendengar dan melihat dari segi penontonnya, juga harus dilihat dari segi kenyamanan pemainnya. Agar pemain masih bisa leluasa dalam melakukan aksi panggungnya, maka rentang sudut yang masih bisa ditolerir $135^{\circ}$ dari sumber bunyi seperti yang dijelaskan oleh Mills (1976:37):
Greater encirclement has the obvious advantage of bringing more members of the audience within good acoustics and visual distance of the stage, but it also means that they will tend to be distracted in some instances by the audience on the other side of the acting area. Furthermore, it is not possible for an actor to convey focial expressions and gestures in two opposite directions at the same time, an angle $135^{\circ}$ is generally considered to be the limit, and greater encirclement can therefore impose constraints on the type of performance undertaken.

Lingkar area tempat duduk penonton yang lebih besar merupakan hal yang menguntungkan karena lebih banyak penonton yang mendapatkan jarak mendengar dan melihat yang baik secara akustik maupun visual, tapi dalam beberapa hal cenderung tidak menguntungkan bagi penonton yang berada di sisi panggung yang lain. Lagipula, tidak mungkin bagi pemain untuk menghadap ke arah penonton yang berada di dua arah yang berlawanan dalam waktu yang bersamaan.

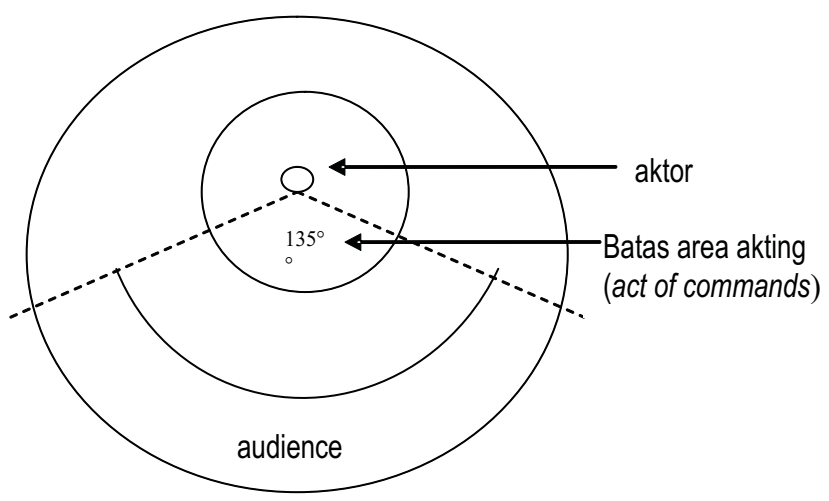

Gambar 7. Limit Lingkar area penonton yang dapat dijangkau pemain (act of command)

Sumber: Doelle (1990)

Lingkar dengan sudut $135^{\circ}$ merupakan batas maksimal, karena lebih dari itu akan menambah ketidakleluasaan penampilan pemain saat melakukan pertunjukan.

\section{Pemilihan Bentuk Ruang yang Tepat}

Doelle (1995:95) menyebutkan bahwa bentuk ruang juga mempengaruhi kualitas bunyi. Ada beberapa bentuk ruang pertunjukan yang lazim digunakan, yaitu: bentuk empat persegi (rectangular shape), bentuk kipas (fan shape), bentuk tapal kuda (horse-shoe shape) dan bentuk hexagonal (hexagonal shape). 
Bentuk Ruang Empat Persegi (rectangular shape) merupakan bentuk tradisional yang paling umum digunakan Ruang-ruang konser dari abad ke-19 dan awal abad ke-20 seperti The Grosser Musikvereinsaal, Vienna, Andrew's Hal Glasgow, The Concertgebouw Amsterdam, The Stadt Casino Basel dan Symphony Hall Boston, semuanya mempunyai bentuk lantai empat persegi. Keuntungan dar bentuk ruang ini dijelaskan Mills (1976:28) sebagai berikut:

The virtues of this shape are a high degree of uniformity and in inherently good balance of early and late energy. The small width is responsible for a substantial amount of early lateral sound, enhanced by additional contribution of multiple reflections between the side walls

Jadi bentuk ruang empat persegi panjang (rectangular shape) memiliki tingkat keseragaman suara yang tinggi sehingga terjadi keseimbangan antara suara awal dan suara akhir. Sisi lebar yang lebih kecil dapat merespon bunyi latera /bunyi samping, diperkuat dengan pantulan yang berulang-ulang antar dinding samping menyebabkan bertambahnya kepenuhan nada, suatu segi akustik ruang yang sangat diinginkan pada ruang pertunjukan.

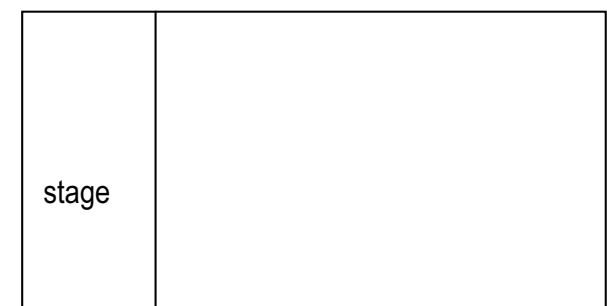

Gambar 8. Bentuk lantai empat persegi (Rectangular shape)

$$
\text { Sumber: Doelle (1990) }
$$

Kelemahan dari bentuk ini adalah pada bagian sisi panjangnya, karena menjadikan jarak antara penonton dengan panggung terlalu jauh.Solusi untuk permasalahan ini adalah dengan mempersempit area panggung dan memperlebar sisi depannya.

Lantai bentuk Kipas (Fan Shape) membawa penonton dekat dengan sumber bunyi karena memungkinkan adanya konstruksi balkon. Keuntungan lain dari bentuk ini menurut Mills (1986: 29):

The fan shape has the advantage of containing the maximum number of people in a given angle for a specified maximum source receiver distance. This characteristic is attractive for economic reason as well as enabling the hall to fulfil multi purpose requirements.
Jadi keuntungan ruang bentuk kipas, dapat menampung penonton dalam jumlah banyak, disamping itu juga menyediakan sudut pandang yang maksimum bagi penonton.

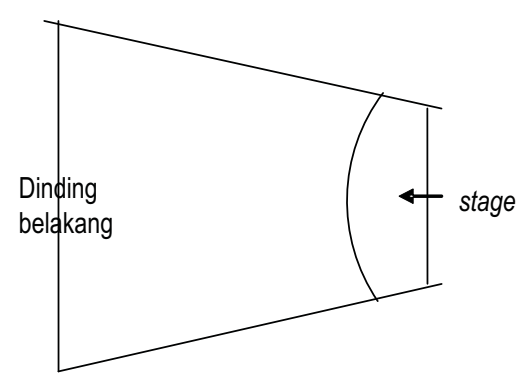

Gambar 9. Denah Gedung Pertunjukan dengan bentuk kipas Sumber: Doelle (1990)

Akan tetapi disisi lain, banyak pula kekurangan dari bentuk ini memiliki kekurangan yang membuat reputasi akustiknya kurang baik, karena bentuk dinding samping yang melebar ke belakang menyebabkan pemantulan yang terlalu cepat ke dinding belakang yang dilengkungkan sehingga menciptakan gema dan pemusatan bunyi sehingga ruang ini cenderung memiliki akustik yang tidak seragam, dengan kondisi area duduk penonton bagian tengah yang kurang baik.

Ruang Bentuk Tapal Kuda (Horse-shoe shape) merupakan bentuk yang memiliki keistimewaan karakteristik yakni adanya kotak-kotak yang berhubungan (rings of boxes) yang satu di atas yang lain.Walaupun tanpa lapisan permukaan penyerap bunyi pada interiornya, kotak-kotak ini berperan secara efisien pada penyerapan bunyi dan menyediakan waktu dengung yang pendek.Disamping itu bentuk dindingnya membuat jarak penonton dengan pemain menjadi lebih dekat. (Doelle:1990).

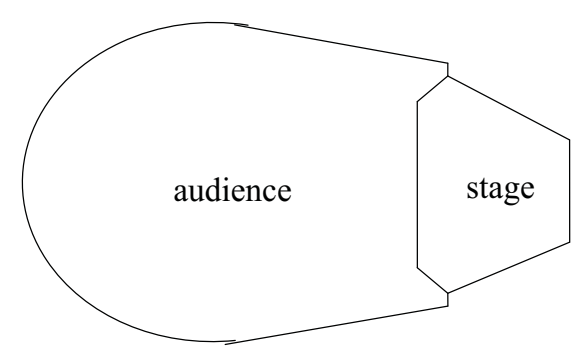

Gambar 10. Ruang berbentuk Tapal Kuda (Horse-shoe Shape) Sumber: Doelle (1990) 
Akan tetapi disisi lain terdapat kekurangan yaitu permukaan dinding bagian belakang yang cekung merupakan bentuk yang tidak dianjurkan karena akan terjadi penyerapan suara yang terlalu tinggi di bagian belakang.

Bentuk Lantai Hexagonal (Hexagonal Shape) di di bawah ini dapat membawa penonton sangat dekat dengan sumber bunyi, keakraban akustik dan ketegasan, karena permukaan-permukaan yang digunakan untuk menghasilkan pemantulan-pemantulan dengan waktu tunda singkat dapat dipadukan dengan mudah ke dalam keseluruhan rancangan arsitektur.

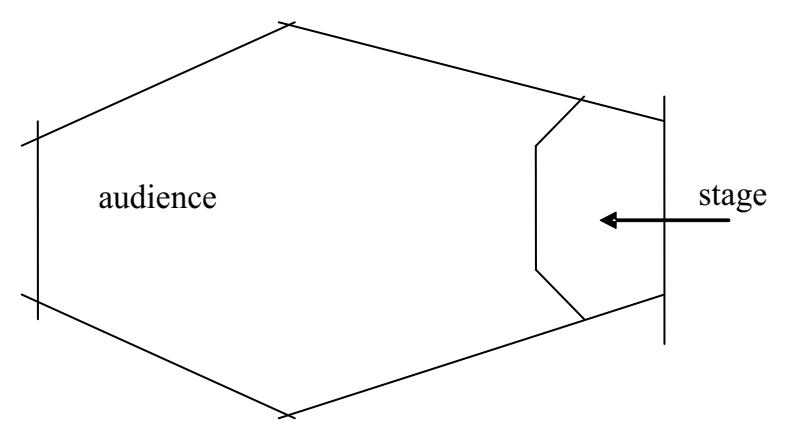

Gambar 11. Bentuk Lantai Hexagonal (Hexagonal Shape) Sumber: Doelle (1990)

\section{Distribusi Bunyi yang Merata}

Energi bunyi dari sumber bunyi harus terdistribusi secara merata ke setiap bagian ruang, baik yang dekat maupun yang jauh dari sumber bunyi. Untuk mencapai keadaan tersebut menurut Doelle (1990:60) perlu diusahakan pengolahan pada elemen pembentuk ruangnya, yakni unsur langit-langit, lantai dan dinding, dengan cara membuat permukaan yang tidak teratur, penonjolan elemen bangunan, langit-langit yang ditutup, kotak-kotak yang menonjol, dekorasi pada permukaan dinding yang dipahat, bukaan jendela yang dalam dan sebagainya.

Pengolahan bentuk permukaan elemen pembentuk ruang terutama dibagian dinding dan langit-langit dengan susunan yang tidak teratur dan dalam jumlah dan ukuran yang cukup akan banyak memperbaiki kondisi dengar, terutama pada ruang dengan waktu dengung yang cukup panjang.

\section{Ruang Harus Bebas dari Cacat-Cacat Akustik}

Cacat akustik merupakan kekurangan-kekurangan yang terdapat pada pengolahan elemen pembentuk ruang gedung pertunjukan yang menimbulkan permasalahan akustik. Adapun cacat akustik yang biasa terjadi pada sebuah gedung pertunjukan yang tidak di desain dengan baik menurut Doelle (1990:64) ada delapan jenis, yakni: gema/echoes, pemantulan yang berkepanjangan (long delayed reflections), gaung, pemusatan bunyi, ruang gandeng (coupled spaces), distorsi, bayangan bunyi, dan serambi bisikan (whispering gallery).

Gema (echoes) merupakan cacat akustik yang paling berat, terjadi bila bunyi yang dipantulkan oleh suatu permukaan tertunda cukup lama untuk dapat diterima dan menjadi bunyi yang berbeda dari bunyi yang merambat langsung dari sumber suara ke pendengar. Terkait dengan hal ini Mills (1990:28) berpendapat: Reflections off large plane surfaces risk being heard as echoes, that is discrete delayed repetitions of the direct sound. Jadi pemantulan suara yang mengenai permukaan datar yang lebar beresiko terdengar sebagai gema, yang ditandai dengan adanya penundaan yang berulang-ulang dari bunyi langsung.

Pemantulan yang Berkepanjangan (Long - Delayed Reflections) adalah cacat akustik yang sejenis dengan gema, tetapi penundaan waktu antara penerimaan bunyi langsung dan bunyi pantul agak lebih singkat, sedangkan gaung merupakan cacat akustik yang terdiri atas gema-gema kecil yang berturutan dengan cepat. Peristiwa ini dapat diamati bila terjadi ledakan singkat seperti tepukan tangan atau tembakan yang dilakukan di antara dua permukaan dinding atau pemantul bunyi yang sejajar dan rata.Waktu dengung (reverberation time) berperan penting dalam menciptakan kualitas musik dan kemampuan untuk memahami suara percakapan dalam ruang. Ketika permukaan ruang memiliki daya pantul yang tinggi, bunyi akan terus memantul atau menggema secara berlebihan sehingga mengakibatkan bunyi tidak dapat didengar dan dimengerti dengan jelas .

Pemusatan Bunyi atau disebut juga dengan hot spots atau titik panas, merupakan cacat akustik yang disebabkan oleh pemantulan bunyi pada permukaan-permukaan cekung.Intensitas bunyi di titik panas sangat tinggi dan merugikan daerah dengar karena menyebabkan distribusi energi bunyi tidak dapat merata.

Ruang Gandeng (Coupled Spaces) merupakan cacat akustik yang terjadi bila suatu ruang pertunjukan berhubungan langsung dengan ruang lain seperti ruang depan dan ruang tangga, maka kedua ruang tersebut membentuk ruang gandeng. Selama rongga udara ruang yang bergandengan tersebut terbuka maka masuknya bunyi dengung dari ruang lain tersebut akan terasa meski dengung di dalam ruang pertunjukan telah diatasi dengan baik.Gejala ini akan mengganggu penonton yang duduk dekat pintu keluar masuk yang terbuka.

Distorsi merupakan cacat akustik yang disebabkan oleh perubahan kualitas bunyi yang tidak dikehendaki. Hal ini terjadi akibat ketidakseimbangan atau penyerapan bunyi yang terlalu besar oleh permukaan-permukaan dinding.

Bayangan Bunyi merupakan cacat akustik yang terjadi apabila bunyi terhalang untuk sampai ke penonton. Gejala ini dapat diamati pada tempat duduk 
di bawah balkon yang menonjol terlalu jauh dengan kedalaman lebih dari dua kali tingginya.

Serambi Bisikan (Whispering Gallery) merupakan cacat akustik yang disebabkan oleh adanya frekuensi bunyi tinggi yang mempunyai kecenderungan untuk merangkak sepanjang permukaan-permukaan cekung yang besar (kubah setengah bola). Suatu bunyi yang sangat lembut seperti bisikan yang diucapkan di bawah kubah tersebut akan terdengar pada sisi yang lain. Meskipun gejala ini kadang menyenangkan dan tidak merusak, akan tetapi tetap saja merupakan suatu keadaan yang tidak diinginkan bagi akustik yang baik.

\section{Penggunaan Bahan Penyerap Bunyi}

Pemilihan bahan penyerap bunyi yang tepat untuk melapisi elemen pembentuk ruang gedung pertunjukan sangat dipersyaratkan untuk menghasilkan kualitas suara yang memuaskan. Doelle (1990:33) menjelaskan mengenai bahanbahan penyerap bunyi yang digunakan dalam perancangan akustik yang dipakai sebagai pengendali bunyi dalam ruang-ruang bising dan dapat dipasang pada dinding ruang atau di gantung sebagai penyerap ruang yakni yang berjenis bahan berpori dan panel penyerap (panel absorber) serta karpet.

\section{Bahan Berpori}

Bahan berpori merupakan suatu jaringan selular dengan pori-pori yang saling berhubungan. Bahan akustik yang termasuk kategori ini adalah papan sera (fiber board), plesteran lembut (soft plasters), mineral wools dan selimut isolasi.

Karakteristik dasar dari semua bahan berpori seperti ini adalah mengubah energi bunyi yang datang menjadi energi panas dalam pori-pori dan diserap, sementara sisanya yang telah berkurang energinya dipantulkan oleh permukaan bahan.Bahan akustik berpori dapat dibagi menjadi 2 kategori, yakni: unit akustik siap pakai, dan bahan yang disemprotkan.

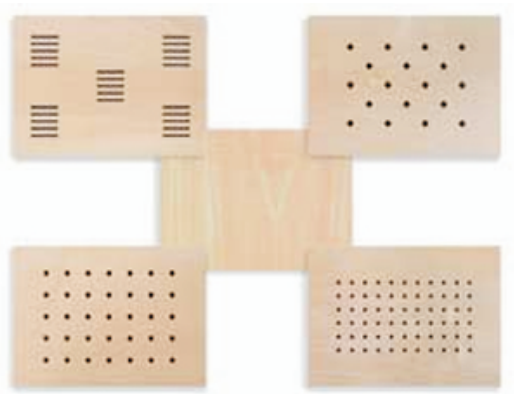

Gambar 12. Unit akustik siap pakai yang berlubang dan bercelah Sumber: http://www.acoustics.com/product
Unit akustik siap pakai meliputi bermacam-macam jenis ubin selulosa dan serat mineral yang berlubang, bercelah, bertekstur, panel penyisip dan lembaran logam berlubang dengan bantalan penyerap.Jenis-jenis ini dapat dipasang dengan berbagai cara, sesuai dengan petunjuk pabrik seperti disemen pada permukaan yang padat, dipaku, dibor pada kerangka kayu atau dipasang pada sistem langitlangit gantung. Unit akustik siap pakai khusus seperti acoustical board untuk pelapis dinding dan Geocoustic board dipasang pada langit-langit dalam susunan dengan jarak tertentu dalam potongan-potongan kecil.

Penggunaan bahan akustik siap pakai ini juga menguntungkan ditinjau dari daya serap bunyinya yang dijamin oleh pabrik, pemasangan dan perawatannya mudah, dapat dihias tanpa mempengaruhi jumlah penyerapan, penggunaannya dalam sistem langit-kangit dapat disatukan secara fungsional dan visual dengan instalasi penerangan, pemanasan dan pengkondisian udara. Apabila dipasang dengan tepat maka penyerapannya dapat bertambah.

Bahan yang disemprotkan digunakan terutama untuk tujuan reduksi/ pengurangan bising. Bahan ini berbentuk semiplastik, diterapkan dengan cara disemprotkan melalui pistol penyemprot/sprayer gun. Kelebihan dari bahan akustik jenis ini adalah fleksibilitasnya karena berbentuk cairan yang disemprotkan ke permukaan sehingga dapat diterapkan pada bentuk penampang apapun. Biasanya diterapkan pada ruang dalam auditorium dimana upaya pengolahan akustik lain tidak dapat dilakukan karena bentuk permukaan yang melengkung atau tidak teratur.Efisiensi akustiknya biasanya cukup baik apabila dikerjakan dengan cermat, tepat dalam penentuan komposisi plesteran, jumlah perekat, serta keadaan lapisan dasar yang digunakan.

\section{Penyerap Panel}

Penyerap panel merupakan bahan kedap yang dipasang pada lapisan penunjang yang padat (solid baking) tetapi terpisah oleh suatu rongga.

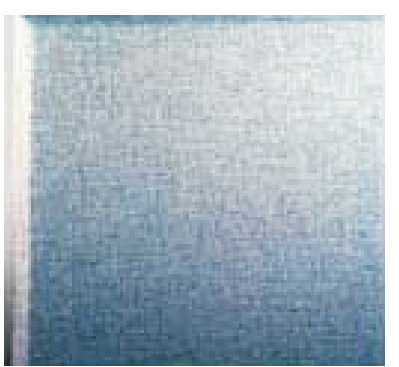

Gambar 13. Panel Penyerap (Panel Absorber) siap pakai yang bertekstur Sumber: http://www.acoustics.com/product 
Bahan ini berfungsi sebagai penyerap panel dan akan bergetar bila tertumbuk oleh gelombang bunyi. Getaran lentur dari panel akan menyerap sejumlah energi bunyi yang datang dan mengubahnya menjadi energi panas. Cara pemasangan sesuai dengan di semen pada permukaan yang padat, dipaku, dibor pada kerangka kayu atau dipasang pada sistem langit-langit gantung.

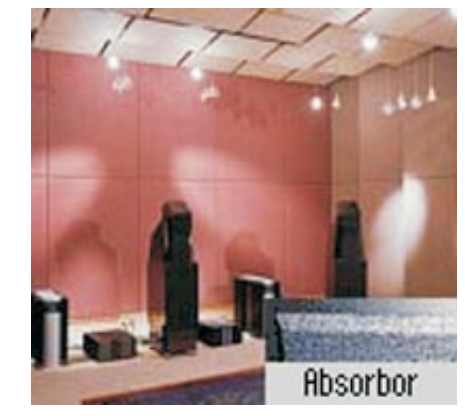

Gambar 14. Penerapan Panel Penyerap pada plafond dan dinding Sumber: http://www.acoustics.com/product

Kelebihan dari bahan ini adalah kemudahannya untuk disusun sesuai desain yang diinginkan karena tersedia dalam ukuran-ukuran yang bervariasi, mudah dalam pemasangannya serta ekonomis dan merupakan penyerap bunyi yang efisien karena menyebabkan karakteristik dengung yang merata pada seluruh jangkauan frekuensi (tinggi maupun rendah karena berfungis untuk mengimbangi penyerapan suara yang agak berlebihan oleh bahan penyerap berpori dan isi ruang.Jenis bahan yang termasuk penyerap panel antara lain: panel kayu, hardboard, gypsum board dan panel kayu yang digantung di langit-langit.

\section{Karpet}

Karpet selain digunakan sebagai penutup lantai, juga digunakan sebagai bahan akustik karena kemampuannya mereduksi dan bahkan meniadakan bising benturan dari atas atau dari permukaan seperti suara seretan kaki, bunyi langkah kaki, pemindahan perabot rumah dan sebagainya. Karpet juga dapat diterapkan sebagai bahan pelapis dinding, untuk memberikan peredaman suara yang lebih optimal. Makin tebal dan berat karpet maka makin besar pula daya serap dan kemampuannya dalam mereduksi bising.

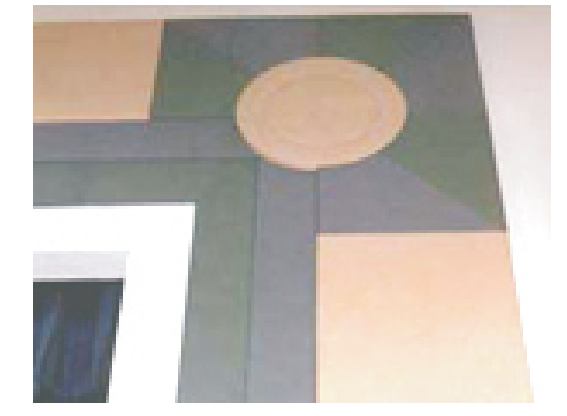

Gambar 15. Bahan akustik dari Karpet Sumber: http://www.acoustics.com/product

\section{SIMPULAN}

Dari uraian di atas dapat disimpulkan bahwa persyaratan utama yang harus dipenuhi dalam perancangan tata akustik gedung pertunjukan adalah: kekerasan (loudness) yang cukup dengan cara memperpendek jarak penonton dengan sumber bunyi, penaikan sumber bunyi, pemiringan lantai, sumber bunyi harus dikelilingi lapisan pemantul suara, kesesuaian luas lantai dengan volume ruang, menghindari pemantul bunyi paralel yang saling berhadapan dan penempatan penonton di area yang menguntungkan. Persyaratan lainnya adalah bentuk ruang yang tepat, distribusi energi bunyi yang merata dalam ruang, ruang harus bebas dari cacat-cacat akustik dan pengolahan elemen pembentuk ruangnya (lantai, dinding dan plafond) dengan bahan penyerap bunyi dan bahan yang berfungsi akustik seperti acoutical board maupun bahan-bahan lunak yang berpori lainnya. Keberadaan plafond yang memenuhi syarat baik bahan maupun bentuk penampangnya juga mutlak, untuk menghindari melemahnya suara.Penggunaan lantai yang keras dan tidak dapat ditembus (batubata, beton) dan tidak dilapis hanya akan menyerap kurang dari $5 \%$ suara dan memantulkan hampir $95 \%$. Pemasangan karpet diseluruh permukaan lantai, pemasangan tirai dan penggunaan kursi penonton dengan jok yang empuk juga sangat membantu penyerapan bunyi yang sangat dibutuhkan untuk menghasilkan bunyi yang nyaman didengar.

Tulisan ini diharapkan dapat menjadi masukan dalam perancangan maupun perbaikan gedung pertunjukan meskipun pertimbangan finansial biasanya merupakan pembatas langkah-langkah perbaikan akustik, karena untuk menghasilkan kualitas akustik yang baik memerlukan biaya tinggi.

\section{DAFTAR PUSTAKA}

Doelle, Leslie E. 1990. Akustik Lingkungan. Jakarta: Erlangga

Halme, Arthur.1991. Space. Finlandia: Finnish Interior

Mill, Edward D. 1976. Planning, London: Newness-Butterworth 
104 imasi, Vol.7, No. 1, Februari 2009: 88 - 104

Pamudji Suptandar. 1982. Interior Design. Jakarta:Usakti

Reznikoff, SC. 1979. Specifications for Commercial Interiors. New York: First Printing

John M. Echols dan Hassan Shadily. 1987. Kamus Inggris Indonesia. Jakarta: Gramedia

W.J.S. Poerwadarminta. 1976. Kamus Umum Bahasa Indonesia. Jakarta: Balai Pustaka 